\title{
Traction animale et association agriculture élevage dans les savanes d'Afrique de l'Ouest et du Centre. D'un modèle techniciste à une démarche d'intégration raisonnée à différentes échelles
}

\author{
P. Dugué ${ }^{1}$ A.L. Dongmo Ngoutsop ${ }^{2}$
}

\begin{abstract}
Mots-clés
Polyculture élevage - Système d'exploitation agricole - Culture attelée - Energie animale - Gestion foncière - Développement rural Développement régional Afrique au sud du Sahara.
\end{abstract}

\begin{abstract}
Résumé
En Afrique subsaharienne, les agronomes ont longtemps considéré que l'amélioration des performances des exploitations agricoles reposait sur l'intégration de l'élevage à l'agriculture. Ce modèle de production s'appuyait sur la traction animale, les cultures fourragères et l'élevage bovin viande et lait, base de la production de fumure organique. Mais, ce modèle n'a pas été adopté comme prévu. Dans le bassin arachidier au Sénégal, dans un contexte de fort aléa climatique, la priorité des paysans est de travailler rapidement pour implanter et entretenir les cultures, ce qui explique leur préférence pour la traction équine. Au Nord-Cameroun la stratégie d'accroissement des surfaces cultivées s'appuyant sur la traction bovine a été préférée à celle d'augmentation des rendements ; la fumure animale a longtemps été délaissée. Cette stratégie reste encore possible dans les zones peu ou moyennement peuplées. Dans les zones les plus peuplées, les évolutions des systèmes de production sont comparables à celles observées dans le bassin arachidier : développement de la traction asine et de l'embouche bovine, difficulté à associer élevage bovin extensif et agriculture. A l'échelle de vastes régions, il sera toujours nécessaire de valoriser par l'élevage des espaces difficiles à cultiver. L'accès à ces espaces pour des troupeaux transhumants doit être préservé. II est aussi envisageable de développer des complémentarités entre des systèmes d'élevage périurbains et des zones agricoles proches qui développeraient des filières d'approvisionnement en fourrages et en aliments du bétail. Au niveau des terroirs villageois et des exploitations agricoles, l'intensification de l'élevage est indispensable mais nécessite de revoir les conduites des troupeaux et surtout d'accroître la production et les règles de gestion de la biomasse végétale. Pour cela la traction animale devrait être plus mobilisée pour assurer les transports (fumier, fourrage, etc.), accroître les revenus (vache de trait, embouche des animaux de trait en fin de carrière) et contribuer à développer des systèmes de culture plus productifs et accordant plus de place à la production fourragère.
\end{abstract}

\footnotetext{
1. Cirad, département Tera, TA 60/15, 73 rue Jean-François Breton, 34398 Montpellier Cedex 5, France

E-mail : patrick.dugue@cirad.fr

2. Irad, station de Garoua, BP 415, Garoua, Cameroun

E-mail : dongmonal@yahoo.fr
}

\section{INTRODUCTION}

Depuis une trentaine d'années, on observe, dans les zones de savanes d'Afrique subsaharienne, un développement conjoint de l'agriculture et de l'élevage dans les mêmes territoires et bien souvent au sein des mêmes unités de production. Auparavant, l'agriculture et l'élevage étaient gérés séparément par des populations d'origine différente : les agriculteurs ou paysans, les éleveurs ou pasteurs.

Jusque dans les années 1970, les politiques de développement ont promu, dans ces régions et pour les agriculteurs, un système de production basé sur l'intégration agriculture élevage, s'appuyant sur l'utilisation d'intrants (engrais minéraux, produits vétérinaires), 
la traction animale, les cultures fourragères et un noyau d'élevage bovin. Ce type d'intégration devait améliorer la productivité des exploitations familiales s'adonnant habituellement à une agriculture manuelle d'autosubsistance. Il s'inspire du modèle de production agricole du nord de l'Europe, caractérisé par la révolution fourragère apparue dès la fin du XVIII ${ }^{\mathrm{e}}$ (18). Ce modèle productiviste a très peu diffusé en Afrique subsaharienne, car il avait été raisonné à l'échelle de l'unité de production sans prendre en compte l'organisation sociale préexistante et la gestion collective des ressources, en particulier des terres agricoles et des parcours (14). L'intensification des systèmes de culture et d'élevage se conçoit pleinement lorsque l'objectif central des producteurs est d'accroître les rendements (la productivité de la terre) dans un contexte de saturation foncière. Dans le cas des savanes africaines à cette période et dans bien des cas encore aujourd'hui, le territoire des exploitations évolue avec le temps en fonction des possibilités de défricher de nouvelles terres et des stratégies des agriculteurs à étendre leur foncier. La traction animale a été un moyen efficace pour mettre en œuvre cette stratégie. Si dans bien des cas elle n'a pas entraîné une augmentation des rendements mais plutôt de la surface cultivée par actif, son développement continu depuis 40 ans marque le début de l'intégration de l'élevage dans les systèmes de production dominés par les productions végétales. En s'appuyant sur des études réalisées dans le bassin arachidier au Sénégal et la zone cotonnière au Nord-Cameroun, on caractérisera les évolutions de l'association agriculture élevage dans les exploitations agricoles en insistant sur la place et le rôle de la traction animale dans ce processus. On abordera ensuite les questions de coordination entre agriculteurs, agroéleveurs et éleveurs à l'échelle de territoires soumis à une croissance démographique continue. Enfin, on discutera de l'accompagnement des processus d'innovation technique et organisationnelle permettant dans ce contexte d'assurer un développement durable.

\section{- DEVELOPPEMENT DES SYSTEMES MIXTES AGRICULTURE ELEVAGE DANS LE BASSIN ARACHIDIER SENEGALAIS ET LA ZONE COTONNIERE DU CAMEROUN}

\section{Prémices de l'intégration grâce au développement de la traction animale et des cultures commerciales}

Les cultures commerciales - l'arachide au centre du Sénégal et le coton au Nord-Cameroun - constituent le pivot de l'économie agricole de ces deux régions. Actuellement la densité de population rurale sans cesse croissante (plus de $60 \mathrm{hab} . / \mathrm{km}^{2}$ dans plus des deux tiers du bassin arachidier et dans plus de la moitié de la zone cotonnière au Cameroun) entraîne une compétition entre agriculteurs et éleveurs pour l'occupation de l'espace et l'accès aux ressources en terres cultivables et de parcours. L'élément principal de différenciation de ces deux régions est la pluviosité : l'agriculture du bassin arachidier sénégalais est fortement contrainte par une pluviosité annuelle faible et irrégulière (de 400 à $650 \mathrm{~mm} / \mathrm{an}$ environ) alors que celle de la zone cotonnière au Cameroun est plus abondante (700-1 $200 \mathrm{~mm}$ ) et mieux répartie au cours de la campagne agricole, sauf dans sa partie septentrionale (figure 1). Malgré ces contraintes climatiques, des stratégies variées portées par les Etats et les paysans ont favorisé l'émergence des cultures de vente.

Dans les années 1960, l'Etat sénégalais affecte d'importants moyens pour équiper les exploitations agricoles et leur faciliter l'accès aux engrais minéraux et aux semences sélectionnées, ce qui permet d'augmenter la production d'arachide, premier produit d'exportation. Les paysans optent rapidement pour une culture attelée « légère »- traction équine, semoir, outils de sarclage simplifiés - bien adaptée aux sols sableux et aux contraintes

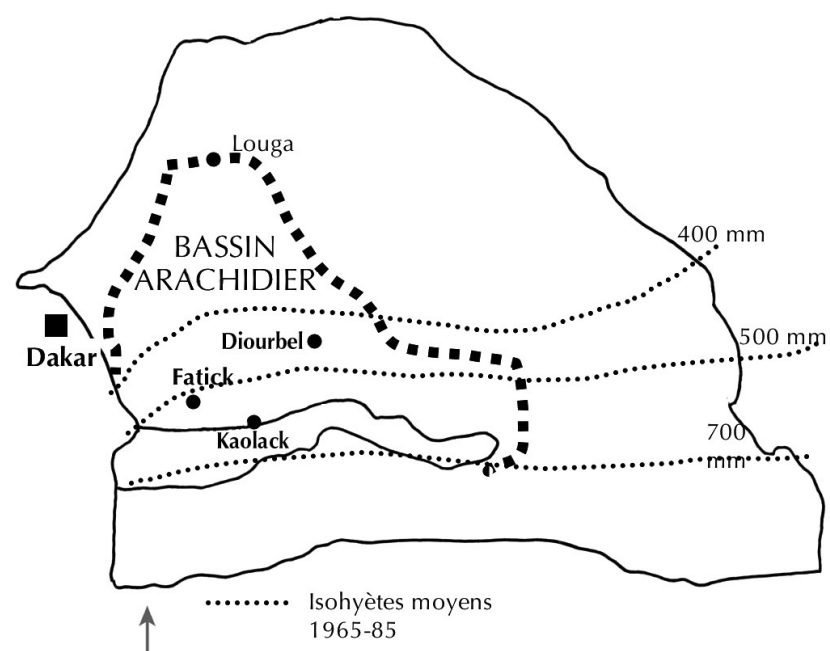

a) Bassin arachidier au Sénégal

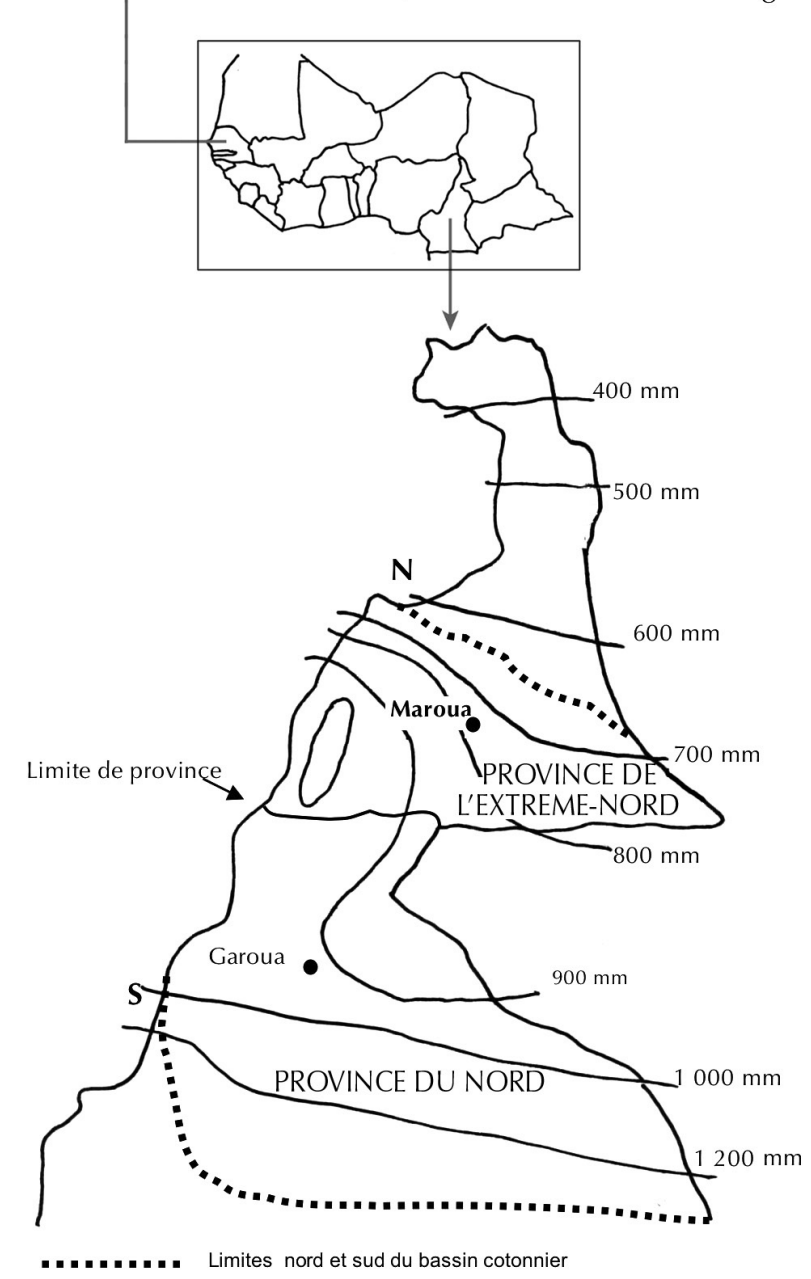

b) Zone cotonnière au nord du Cameroun

Figure 1 : carte de situation du bassin arachidier au Sénégal et de la zone cotonnière au Cameroun.

pluviométriques du fait de sa rapidité d'intervention (1, 15). A la fin des années 1970, la quasi-totalité des exploitations agricoles du bassin arachidier dispose d'au moins une unité de traction (un cheval ou plus rarement une paire de bœufs ou un âne). Ce niveau d'équipement qui se maintient (3) permet à l'arachide d'occuper jusqu'à la fin des années 1990 environ 50 p. 100 de l'assolement 
régional. L'introduction de la culture cotonnière au Nord-Cameroun dans les années 1960-70 a nécessité, puis a encouragé la diffusion de la traction animale $(24,25)$. L'accès aux équipements et aux intrants (engrais et insecticides) est facilité par un système de crédit géré par la société cotonnière publique. La charrue bovine est préférée dans un premier temps ; elle permet aux exploitants d'étendre les surfaces cultivées par un labour permettant d'enfouir les adventices pendant les deux premiers mois de saison des pluies avant le semis du cotonnier.

Dans les deux régions, l'adoption de la traction animale constitue la première véritable expérience d'élevage pour les agriculteurs, sauf pour les Sereer et les Toupori qui pratiquent traditionnellement l'élevage $(19,20)$. Elle contribue à transformer leurs habitudes et pratiques et leur ouvre de nouvelles perspectives économiques. Cependant, la faible production de biomasse fourragère dans les zones les moins pluvieuses reste une contrainte à l'accroissement des effectifs, ce qui restreint l'élevage aux animaux de trait et à quelques petits ruminants intégrés aux exploitations. Dans les zones plus humides (centre et sud du bassin cotonnier, extrême sud $\mathrm{du}$ bassin arachidier) disposant d'une production fourragère plus conséquente sur parcours et à partir des zones cultivées, les modes d'intégration de l'élevage dans les exploitations agricoles sont plus diversifiés : bovins de trait, élevage bovin naisseur ou d'embouche. De plus, ces régions agricoles favorisées accueillent encore des éleveurs transhumants attirés par la production de résidus de récolte fourragers.

Les agriculteurs - à partir des années 1980 dans le bassin arachidier au Sénégal et dans les années 1990 au Nord-Cameroun - adoptent une stratégie basée sur deux composantes principales : i) l'augmentation de la surface consacrée aux productions végétales, notamment grâce à la traction animale ; ii) le développement, à partir des revenus de l'agriculture, d'un élevage associé, dans une double optique de capitalisation et de sécurisation financière des ménages.

L'intensification et l'intégration de l'élevage dans les exploitations agricoles s'illustrent par la progression de l'embouche bovine sous des formes différentes selon les régions $(10,23)$. Dans la zone sud du bassin arachidier sénégalais, l'embouche est progressive sur des bœufs de trait durant leur courte carrière (moins de cinq ans) : ces bovins travaillent, en effet, peu de jours dans l'année car le transport est assuré par les chevaux. Dans le reste du bassin arachidier et au Nord-Cameroun, l'embouche bovine se réalise sur une courte durée (trois mois) pendant la saison sèche sur des animaux maigres achetés bon marché généralement à des éleveurs et sur les bovins de trait en fin de carrière. Cette pratique est facilitée par la disponibilité en main-d'œuvre et en aliment (fane d'arachide au Sénégal, tourteau de coton au Nord-Cameroun, paille de céréales dans les deux situations) et par le développement récent du crédit pour ce type d'activité, au moins au Sénégal.

\section{Evolutions en cours et contraintes actuelles à l'intégration agriculture élevage}

La réduction et le morcellement des espaces de parcours rendent plus difficiles les déplacements des troupeaux et le maintien d'un élevage extensif bovin dans les régions les plus peuplées (au-delà de 50 à 60 hab./ $\left./ \mathrm{km}^{2}\right)(13,21)$. Dans l'hypothèse d'une évolution d'effectifs d'animaux comparable dans deux villages étudiés dans le sud du bassin arachidier en 1987 et 2000 (tableau I), on note que les paysans Wolofs ont plutôt opté pour une réduction des effectifs bovins que de recourir massivement à la transhumance de saison des pluies. On observe par ailleurs dans ces exploitations, d'une part, un maintien de la traction bovine avec l'objectif de poursuivre le système d'embouche «de longue durée » et, d'autre part, une diversification des modes d'épargne et de capitalisation autrement que par l'élevage (acquisition de maison en ville et de taxi-brousse par les plus fortunés). Par contre, les agroéleveurs du pays Sereer au Sénégal et les éleveurs Peuls Mbororo du Nord-Cameroun augmentent la durée de la transhumance vers des zones pastorales. Les zones d'accueil s'éloignent, réduisant ainsi le temps de présence des troupeaux dans les villages et donc leur contribution à l'entretien de la fertilité du sol par le recyclage des résidus de culture.

Les évolutions des filières des cultures de vente (arachide, coton) pourraient réduire la disponibilité en ressources alimentaires pour le bétail et donc remettre en question l'intégration de l'élevage dans les exploitations et l'amélioration de sa conduite. En effet, au Sénégal, le démantèlement du système d'approvisionnement des semences d'arachide à crédit, et la fluctuation du prix d'achat et les retards de paiement de l'arachide-coque liés à la privatisation du système de collecte poussent les paysans à accroître leur surface en mil $(3,11,17)$. Or, à cette réduction de la surface en arachide correspond une baisse de production de fanes, pivot du système fourrager. La filière coton au Nord-Cameroun reste actuellement le seul pourvoyeur d'aliment du bétail qui couvre près de 50 p. 100 des besoins en matière azotée digestible des bovins intégrés aux exploitations cotonnières en saison sèche (6). La privatisation des sociétés cotonnières (au Cameroun mais aussi au Sénégal) pourrait porter préjudice aux agroéleveurs : réduction, voire suppression de l'appui à la traction animale (crédit équipement, conseil zootechnique et vétérinaire) entraînant une diminution des surfaces cultivées et donc de la production de résidus fourragers.

Cependant, l'accroissement de la demande en produits animaux des villes permet à certains éleveurs et agroéleveurs de développer l'embouche, la production laitière ou des élevages à cycle court (volaille et porcin) modifiant ainsi radicalement les flux de fourrages et d'aliments du bétail. Le renchérissement des aliments du bétail (tourteau d'arachide, graine de coton) en période de pénurie fourragère fragilise ces systèmes d'élevage intensif. Mais avant tout, ces producteurs doivent faire face à la fluctuation des prix des

\section{Tableau}

Moyennes d'effectifs d'animaux d'élevage par exploitation agricole dans la région Sud bassin arachidier dans deux situations comparables

\begin{tabular}{lcccccc} 
Sites & Année & $\begin{array}{c}\text { Petits } \\
\text { ruminants }\end{array}$ & Chevaux & Anes & $\begin{array}{c}\text { Bovins } \\
\text { d'élevage }\end{array} \begin{array}{c}\text { Bovins de trait } \\
\text { (dont vaches en \%) }\end{array}$ \\
\hline $\begin{array}{l}\text { Thyssé-Sonkorong }{ }^{1} \\
\text { Keur Bakary }{ }^{2}\end{array}$ & 1980 & 10,2 & 1,1 & 0,1 & 3,8 & $1,3(20 \%)$ \\
& 2000 & 5,7 & 1,5 & 0,1 & 0,5 & $1,2(37 \%)$
\end{tabular}

$1^{1}$ Lhoste, 1987, Iemvt

2 Djimtoloum, 2000, Cnearc 
produits animaux, liés à la concurrence des produits importés (lait, volaille au Sénégal), à l'évolution de la demande du Nigeria (principal débouché des bœufs d'embouche du Nord-Cameroun) et du taux de change de la monnaie de ce pays (le naïra).

Face à ces contraintes, les agriculteurs développent des stratégies pour maintenir l'élevage intégré dans les exploitations, et en premier lieu les animaux de trait et la culture attelée qui sécurisent l'approvisionnement vivrier des familles (rapidité d'intervention, capital rapidement mobilisable en cas de crise alimentaire grave) Pour cela les ressources fourragères disponibles sont de mieux en mieux valorisées. La collecte des pailles de céréales se généralise. Ces résidus fourragers sont de plus en plus appropriés par ceux qui les ont produits, remettant en cause de ce fait le droit de vaine pâture. La constitution de meules de pailles (de mil au Sénégal, de sorgho de saison sèche ou muskwari au Nord-Cameroun) commence à marquer le paysage. Plus particulièrement dans le bassin arachidier, le ramassage des pailles de graminées annuelles en brousse et des gousses de Faidherbia albida et de Piliostigma reticulata se développe et permet de constituer des stocks fourragers pour la saison sèche allant bien au-delà de ceux que procurent les résidus de culture.

\section{- LECTURE DE L'INTEGRATION AGRICULTURE ELEVAGE ET REORIENTATION DU MODELE TECHNICISTE}

\section{Au niveau des exploitations agricoles}

Le modèle d'intégration de l'élevage dans les exploitations agricoles d'Afrique subsaharienne proposé dès les années 1960 était fortement inspiré de celui de l'agriculture européenne du XVIII ${ }^{\mathrm{e}}$ et $\mathrm{XIX}^{\mathrm{e}}$ siècle. Il misait sur la traction animale comme principale source d'énergie et sur l'élevage pour compléter l'alimentation familiale (lait), dégager un revenu et entretenir la fertilité du sol. Cet entretien était assuré par la production de fumure animale mais surtout par la présence d'une sole fourragère (18).

\section{Déconnexion entre systèmes d'élevage et systèmes de culture}

Les relations agriculture élevage ont finalement évolué vers des formes éloignées des prévisions des développeurs (14). En fait les agriculteurs des zones de savanes ont adopté les éléments du modèle qui répondaient le mieux à leurs stratégies principales (tableau II). La traction animale a été adoptée pour son effet décisif sur la productivité du travail dans une perspective d'extension des cultures et non pas pour ses effets escomptés sur les rendements. L'utilisation de la vache pour la traction a peu intéressé les agriculteurs, sauf ceux de la frange méridionale du bassin arachidier au Sénégal fortement sensibilisés à cette pratique par la recherche et les structures de développement dans les années 1970-80 (16). Ces paysans trouvaient plusieurs avantages à cette forme de traction originale : rapidité et docilité des vaches, carrière plus longue que celle des bœufs, production de veaux. Quant aux cultures fourragères et aux étables fumières, leur diffusion dans ces deux régions est restée limitée et localisée $(7,12)$. La relative disponibilité en terres de parcours et en jachère au Nord-Cameroun, et la forte production de biomasse fourragère liée à la culture arachidière au Sénégal ne justifiaient sans doute pas l'adoption de telles innovations, le plus souvent exigeantes en travail.

L'accroissement du cheptel d'élevage a été possible seulement pour les exploitations dégageant une capacité d'investissement supérieure aux besoins de renouvellement ou d'augmentation du nombre d'unités de traction. Mais bien souvent, la conduite de cet élevage de ruminants (préférentiellement de bovins) s'est appuyée sur les parcours communs, les ressources fourragères produites sur l'exploitation étant plutôt réservées au cheptel de trait.

Cette déconnexion entre systèmes de culture et systèmes d'élevage dans l'unité de production s'intensifie lorsque la taille du troupeau augmente et lorsque l'agroéleveur préfère sécuriser l'alimentation du bétail en recourant à la transhumance. Tant que ces possibilités de transhumance ou d'installation quasiment permanente des activités d'élevage hors des terroirs agricoles subsistent, il y a peu de chance que de véritables systèmes de production polyculture

Tableau II

Comparaison entre les objectifs initiaux de l'intégration agriculture élevage et les choix des producteurs

\begin{tabular}{|c|c|c|c|}
\hline \multirow[t]{2}{*}{ Thèmes } & \multirow{2}{*}{$\begin{array}{l}\text { Objectifs visés par le modèle } \\
\text { techniciste } 1960 \text { - } 1980\end{array}$} & \multicolumn{2}{|c|}{ Adaptation par les producteurs et évolution en cours } \\
\hline & & Bassin arachidier Sénégal & Zone cotonnière Cameroun \\
\hline Energie animale & $\begin{array}{l}\text { T bovine préférée avec recours } \\
\text { aussi aux vaches en vue de } \\
\text { constituer un noyau d'élevage }\end{array}$ & $\begin{array}{l}\text { T équine adoptée parfois } \\
\text { associée à T bovine }\end{array}$ & $\begin{array}{l}\text { T asine ou bovine, fonction } \\
\text { des moyens des exploitations }\end{array}$ \\
\hline $\begin{array}{l}\text { Alimentation } \\
\text { du bétail et CF }\end{array}$ & $\begin{array}{l}\text { Sole fourragère (culture pure) avec } \\
\text { comme objectif complémentaire } \\
\text { l'entretien de la fertilité du sol } \\
\text { Aliments concentrés } \\
\text { Production de foin et d'ensilage } \\
\text { d'herbe de brousse }\end{array}$ & $\begin{array}{l}\text { Rejet des CF mais valorisation } \\
\text { optimale des ressources existantes } \\
\text { Tourteau industriel trop coûteux }\end{array}$ & $\begin{array}{l}\text { Valorisation tardive des résidus } \\
\text { de récolte et du tourteau de } \\
\text { coton } \\
\text { Pas de CF, sauf tentative récente } \\
\text { sous l'impulsion de projets }\end{array}$ \\
\hline $\begin{array}{l}\text { Entretien de } \\
\text { la fertilité du sol }\end{array}$ & $\begin{array}{l}\text { Engrais vert et enfouissement par } \\
\text { un labour de fin de saison des pluies } \\
\text { Recyclage des pailles et fabrication } \\
\text { de fumier de ferme }\end{array}$ & $\begin{array}{l}\text { Valorisation de toutes } \\
\text { les déjections animales } \\
\text { Pas de fumier ni d'engrais vert }\end{array}$ & $\begin{array}{l}\text { Valorisation récente } \\
\text { de la poudrette } \\
\text { Pas de fumier ni d'engrais vert }\end{array}$ \\
\hline $\begin{array}{l}\text { Rôle d'un } \\
\text { élevage naisseur }\end{array}$ & $\begin{array}{l}\text { Constitution d'un noyau d'élevage } \\
\text { comme fournisseur d'animaux } \\
\text { de trait et d'embouche }\end{array}$ & $\begin{array}{l}\text { Déconnexion de l'élevage extensif } \\
\text { de celui des animaux de trait } \\
\text { (sauf équin) }\end{array}$ & $\begin{array}{l}\text { Idem : les grands troupeaux } \\
\text { d'agroéleveurs sont } \\
\text { hors exploitation }\end{array}$ \\
\hline
\end{tabular}


élevage voient le jour tels qu'on les avait imaginés dans les années 1960-70. Le maintien de ce type d'élevage extensif reposant sur la mobilité des troupeaux s'explique par ses faibles charges de fonctionnement comparées à celles des élevages intensifs, plus sédentaires et reposant sur un approvisionnement plus coûteux en aliments et en fourrages.

Cette situation pourrait évoluer rapidement par la raréfaction des espaces consacrés spécifiquement à l'élevage. De plus l'accroissement de la demande en produits animaux, déjà constaté au centre du Sénégal comme au Nord-Cameroun, donne certaines chances aux systèmes d'élevage plus intensifiés. Par exemple, au Nord-Cameroun certains éleveurs et agroéleveurs engagés dans ce processus d'intensification commencent à s'intéresser aux cultures fourragères (Brachiaria ruziziensis en culture pure pour les premiers, légumineuses fourragères, comme certaines variétés de niébé fourrager ou Mucuna pruriens associées aux céréales, pour les seconds).

\section{Faible prise en compte de la diversité des types d'exploitation}

Seulement 10 à 20 p. 100 des exploitations agricoles des deux zones d'études ont pu développer un troupeau d'élevage bovin au-delà de la simple paire de bœufs de trait (tableau III). Les trois quarts des exploitations ne possèdent aucun bovin. De ce fait ils ont une faible capacité à développer des synergies entre leurs systèmes d'élevage (de petits ruminants et d'asins ou équins de trait) et leurs systèmes de culture: faible production de fumure organique, faible valorisation des animaux de trait en dehors des travaux culturaux dans l'exploitation, malgré le développement des services de transport observé au Sénégal. Il s'avère donc que le modèle proposé visant la création d'un troupeau bovin alimenté sur l'exploitation ne peut pas s'appliquer à l'ensemble des exploitations de ces régions pour des problèmes d'espaces, de ressources fourragères mais surtout de financement de ce type d'élevage.

Ce constat amène à diversifier les modèles de polyculture élevage pour les rendre plus proches des capacités réelles d'investissement des exploitations agricoles : la traction animale reste pour encore longtemps un besoin essentiel des exploitations ; le développement d'un noyau d'élevage bovin constitue aussi une perspective de développement pour une partie des exploitations dans les régions où la sécurisation de l'alimentation du bétail est envisageable ; mais pour la majorité des exploitations, il faudrait imaginer avec les producteurs d'autres modèles centrés sur d'autres systèmes d'élevage valorisant le travail disponible en saison sèche et des ressources alimentaires peu coûteuses issues ou non de l'exploitation (embouche ovine et bovine, vache de trait, élevage à cycle court).

\section{Impact limité de l'intégration agriculture élevage sur l'entretien de la fertilité du sol}

L'argument majeur en faveur de l'intégration agriculture élevage a toujours été la capacité du bétail à produire de la fumure organique (directement par production de fèces, mais surtout par le piétinement de litières dans des étables fumières et des parcs). La capacité de production de fumure organique d'une exploitation est fortement corrélée à son effectif de bovins. La production de fumure des petits ruminants et des équins/asins est limitée par le fait qu'ils ne peuvent pas (ou difficilement) piétiner des résidus pailleux pour les transformer en fumier. Les techniques manuelles de compostage de résidus de culture nécessitant peu ou pas de bétail s'avèrent très coûteuses en travail et rencontrent peu d'échos en milieu rural (7). De ce fait, seuls les agroéleveurs disposant d'un troupeau bovin peuvent effectivement produire du fumier en grandes quantités. Mais les besoins de leur exploitation en éléments fertilisants sont très importants car leur surface est généralement bien supérieure à celle des exploitations sans bovin.

Par exemple, dans la province du Nord au Cameroun seules les exploitations possédant un effectif bovin important - les éleveurs Peuls avec 40 bovins ou plus, les agroéleveurs avec une quinzaine de têtes - disposent d'une capacité de fumure significative (tableau IV). Ceci implique pour l'éleveur Peul une présence au moins une partie de l'année de son troupeau à proximité de ses parcelles et pour l'agroéleveur un important investissement en travail pour le recyclage des résidus pailleux. Pour les exploitations disposant uniquement d'une ou de deux paires de bœufs et de quelques petits ruminants, ces techniques de production de fumure organique ont un faible impact dans le cas d'un recyclage limité de paille $(1 \mathrm{~kg} /$ jour/bovin sur six mois). L'entretien de la fertilité du sol nécessite dans ce cas, d'une part, un investissement plus important en travail (recyclage de $5 \mathrm{~kg}$ de litière/jour/bovin sur six mois par la technique du parc d'hivernage et, d'autre part, des pratiques d'entretien de la fertilité du sol complémentaires (fumure minérale, plantes de couverture, agroforesterie, etc.). Ces quantifications peuvent expliquer la déception de certains agroéleveurs possédant peu de bovins (une ou deux paires de bœufs de traction) lorsqu'ils ont tenté de produire du fumier. Ils ont jugé cette production très coûteuse en travail et peu efficace au regard de leurs besoins en fumure.

\section{A l'échelle des territoires}

La construction de modèles de production combinant l'élevage et l'agriculture ne peut pas se faire uniquement à l'échelle des

\section{Tableau III}

Fréquence des exploitations avec troupeau bovin dans le sud du bassin arachidier sénégalais (Keur Bakary, année 2000) et en zone cotonnière au Cameroun (Héri, Ourolabo, 1996)

\begin{tabular}{|c|c|c|c|c|}
\hline \multirow[t]{2}{*}{ Type de traction } & \multirow[t]{2}{*}{ Nb. de bovins } & \multicolumn{3}{|c|}{ Fréquence des exploitations des villages (\%) } \\
\hline & & Keur Bakary & Héri & Ourolabo \\
\hline $\begin{array}{l}\text { Sans unité de traction } \\
\text { Asin/équin }\end{array}$ & $\begin{array}{l}0 \\
0\end{array}$ & 74 & 68 & 72 \\
\hline $\begin{array}{l}\text { Asin/équin }+1 \text { paire de bœufs } \\
1 \text { paire de bœufs sans asin } \\
2 \text { paires de bœufs }\end{array}$ & $\begin{array}{l}2 \\
2 \\
4\end{array}$ & 9 & 22 & 22 \\
\hline $\begin{array}{l}\text { Au moins } 2 \text { paires de bœufs }+1 \text { à } 6 \text { bovins d'élevage } \\
\text { Au moins } 2 \text { paires de bœufs }+6 \text { à } 40 \text { bovins }\end{array}$ & $\begin{array}{c}\text { de } 5 \text { à } 10 \\
\text { de } 11 \text { à } 44\end{array}$ & 17 & 10 & 6 \\
\hline
\end{tabular}


Production et utilisation potentielles de la fumure organique selon le type d'exploitation (province du Nord, Cameroun)

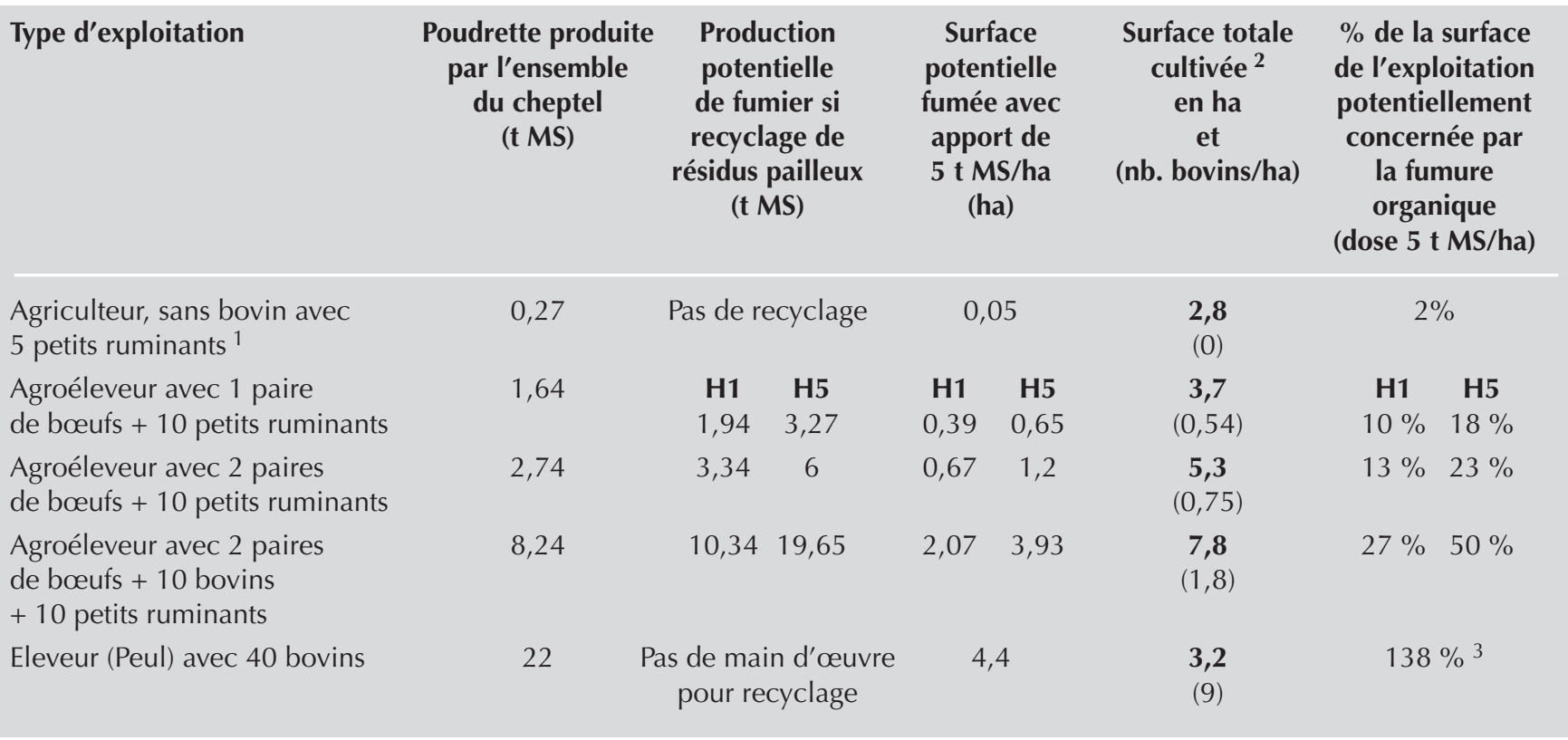

\footnotetext{
${ }^{1}$ On considère que 10 petits ruminants produisent autant de poudrette qu'un bovin UBT mais sans avoir la capacité de transformer la litière

${ }^{2}$ Surface moyenne observée dans la région de Garoua

${ }^{3}$ Dans ce cas l'éleveur Peul peut fumer toutes ses parcelles à $5 \mathrm{t}$ MS/ha et fournir de la fumure à ses voisins

$\mathrm{H} 1$ : hypothèse de recyclage de $1 \mathrm{~kg}$ de paille/jour/bovin pendant 6 mois/an (saison sèche)

$\mathrm{H} 5$ : hypothèse de recyclage de $5 \mathrm{~kg}$ de paille/jour/bovin pendant 6 mois/an (saison sèche) et utilisation du fumier l'année suivante
}

unités de production, surtout en Afrique subsaharienne où subsistent des ressources communes (parcours, vaine pâture, point d'eau, etc.). Les résultats présentés ci-dessus concernent principalement les unités de production des agriculteurs et des agroéleveurs dominées par les productions végétales. Mais l'intégration agriculture élevage doit aussi se raisonner à l'échelle du territoire où se coordonnent les activités des agriculteurs et des pasteurs et où les tensions mais aussi des échanges entre ces deux catégories d'acteurs sont fréquents.

\section{Prendre en compte les échanges et tensions entre unités de production}

Dans les terroirs agrosylvopastoraux cohabitent, généralement, une majorité de petites exploitations ne possédant pas de bovins (65 à 75 p. 100 dans les deux régions étudiées), des paysans propriétaires d'attelages et parfois de bétail (environ 25 p. 100), et quelques éleveurs sédentaires ou transhumants le plus souvent installés à la périphérie du terroir. Les différentes catégories d'unité de production échangent de multiples services qui relèvent bien souvent des relations agriculture élevage (figure 2). En général, les paysans sans bovin dépendent des agroéleveurs pour la location des attelages afin de réaliser les labours et les transports. Inversement, les agroéleveurs qui cultivent de plus grandes surfaces font appel à eux comme main d'œuvre lors des pics de travail (sarclages, récoltes). Il est aussi fréquent qu'ils échangent du travail attelé contre des terres prêtées par des paysans sans attelage. Les agroéleveurs achètent et renouvellent leurs attelages soit directement chez les éleveurs soit sur les marchés à bétail. Les éleveurs interviennent souvent pour les soins du bétail des agriculteurs.

Le bétail des éleveurs résidant à proximité ou transhumant bénéficie du droit de vaine pâture sur l'ensemble des parcelles des agroéleveurs et des paysans sans bovin. Selon les situations, le prélèvement de résidus de culture par le bétail est plus ou moins compensé par une restitution de fumure organique sur les parcelles. En Afrique de l'Ouest (Sénégal, Mali, Burkina Faso, Niger), des contrats de fumure entre agriculteurs et éleveurs subsistent lorsque le territoire de l'agriculteur est suffisamment attractif pour l'éleveur (quantité et qualité des résidus de culture, accès à l'eau et, au besoin, rémunération de l'éleveur sous forme de sel, de tourteau ou d'argent). Généralement en Afrique centrale et particulièrement au Nord-Cameroun, ces relations contractuelles autour de la fumure n'ont pas existé. Les troupeaux des éleveurs séjournent rarement la nuit sur les terres des paysans mais plutôt à la périphérie des terroirs agricoles hors des zones cultivées ou sur leurs propres parcelles qui bénéficient ainsi d'un transfert de fertilité (5).

On constate dans bien des régions (sud du Tchad, Nord-Cameroun) la faiblesse ou l'absence de relations contractuelles entre

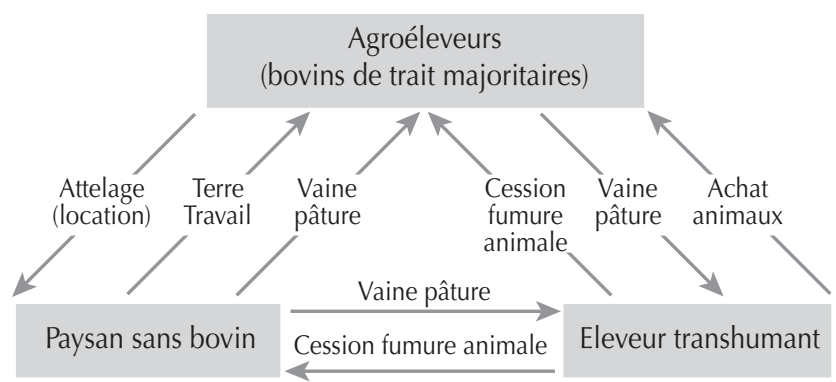

Figure 2 : relations agriculture élevage entre les différents types d'exploitation d'un terroir. 
agriculteurs sans bétail, agroéleveurs et éleveurs. Les situations conflictuelles entre ces catégories d'acteurs sont fréquentes : d'une part, les éleveurs considèrent que le droit de vaine pâture est inaliénable, d'autre part, les agriculteurs ont besoin d'étendre leurs systèmes de culture et donc de mettre en culture une partie des parcours ; ils veulent aussi valoriser pour leur propre bétail leur production de résidus de culture. Au Cameroun comme dans d'autres pays (Côte d'Ivoire, Tchad) les autorités coutumières ou administratives ne cherchent pas à apaiser ces conflits qui constituent pour eux une véritable situation de rente (un arrangement financier ou un don de bovins aux personnes influentes permet d'avoir raison) $(8,22)$.

\section{Complémentarités entre territoires et développement régional}

La place et les rôles de l'élevage vont nécessairement être différents d'une petite région à une autre en fonction des caractéristiques des écosystèmes et des objectifs et savoir-faire des populations qui y vivent. C'est par rapport aux spécificités des situations que l'on peut construire différents modèles de production associant agriculture et élevage. Il implique de replacer ces modèles dans des contextes régionaux plus englobant, où la croissance démographique reste soutenue ainsi que la demande en terre cultivable émanant de la majorité des agriculteurs non propriétaires de bovins d'élevage. Très schématiquement on peut distinguer trois situations d'élevage :

- des zones peu peuplées (moins de 20 hab./ $\mathrm{km}^{2}$ ) où l'élevage extensif peut facilement cohabiter avec l'agriculture. Cet élevage est souvent une garantie d'obtention de bons rendements en céréales par les éleveurs grâce aux apports concentrés de fumure animale. Les paysans sans bovin préfèrent généralement recourir à la jachère pour entretenir la fertilité du sol ;

- des zones en voie de peuplement (20-60 hab./km²) où l'élevage fournit l'énergie de traction et des éléments fertilisants nécessaires à la mise en valeur des terres agricoles. Il permet surtout de constituer une épargne, une trésorerie et un capital nécessaire au développement des exploitations ;

- des zones plus peuplées (plus de $60 \mathrm{hab} . / \mathrm{km}^{2}$ ), dominées par les productions végétales, plus proches des marchés urbains où les éleveurs ont du mal à se maintenir faute d'espace. Dans ces situations, l'intensification de l'élevage serait souhaitable en recourant davantage aux cultures fourragères et sous-produits agricoles en relation avec le développement des filières (viande, lait...). Ceci est déjà remarquable pour les élevages périurbains à cycle court. Mais pour le gros bétail, les éleveurs et agroéleveurs optent plutôt pour une délocalisation de leur élevage en pratiquant la transhumance.

Au-delà de la construction avec les paysans et les pasteurs de modèles de production associant agriculture et élevage spécifiques à leur petite région, il faut travailler à la coordination entre ces deux secteurs d'activité à l'échelle de la grande région. Par exemple, le Nord-Cameroun dispose encore de grands espaces propices à l'élevage (certaines zones de montagnes et de collines peu intéressantes pour l'agriculture, des plaines inondables et des zones très peu peuplées). La meilleure façon de les valoriser reste l'élevage sédentaire mais surtout transhumant, à condition de mettre en relation ces diverses petites régions pour faciliter le déplacement des troupeaux entre des zones pastorales de saison des pluies et celles de saison sèche (dont certaines zones agricoles où le droit de vaine pâture serait négocié avec les agriculteurs). A cette échelle il est difficile aux producteurs et même aux responsables locaux (chef de village et de campements) $\mathrm{d}$ 'avoir une vision globale du fonctionnement de la région et, de ce fait, de participer à l'élaboration de politiques d'aménagement du territoire. Inversement, les services publics et l'administration territoriale ont montré leurs limites dans la gestion des espaces, la plupart des couloirs de transhumance et des pistes à bétail délimités dans les années 1960-70 n’ont pas été respectés par les populations. Même à l'échelle de la petite région, les programmes "gestion de terroir » administrés par des projets et les services publics au début des années 1990 n'ont pas connu beaucoup de succès faute d'une prise en compte effective des stratégies des différents groupes de producteurs. Il convient d'imaginer de nouveaux modes de concertation entre acteurs afin qu'ils débattent de l'avenir de leur région et des modes de mise en valeur des ressources naturelles les plus appropriés. Les politiques de décentralisation à l'échelle de la commune rurale mais surtout de la région (dans les pays qui ont opté pour cette forme de décentralisation) peuvent y contribuer.

\section{QUELS ENSEIGNEMENTS POUR DEVELOPPER LES SYNERGIES ENTRE AGRICULTURE ET ELEVAGE}

Des modifications des stratégies de commercialisation des sousproduits agricoles sont possibles avec la poursuite de la privatisation des sociétés cotonnières et des huileries (tourteaux de coton et d'arachide orientés vers l'exportation). Les agriculteurs producteurs et utilisateurs de résidus fourragers pourraient aussi remettre en question le droit de vaine pâture et valoriser euxmêmes ces ressources avec leur bétail ou en les commercialisant. Ces évolutions modifieraient en profondeur l'offre en aliments du bétail et donc les systèmes de production des pasteurs et des agroéleveurs des zones de savane. Sans sous-estimer ces modifications à venir, le principal facteur d'évolution des systèmes de production agricole demeure l'accroissement de la population rurale.

Tant que la pression foncière reste relativement limitée (région à moins de 40 hab. $/ \mathrm{km}^{2}$ ), les activités agricoles et l'élevage pastoral peuvent cohabiter sans générer de conflits ni entraîner une dégradation des ressources naturelles. Dans ce cas la priorité est de préserver ces ressources par des défrichements raisonnés et une gestion des jachères sur la durée afin d'éviter le mitage de l'espace pastoral en cas d'installation de nouveaux agriculteurs. Lorsque la pression foncière dépasse le seuil de $60 \mathrm{hab} . / \mathrm{km}^{2}$, et en l'absence de modification des pratiques et d'entente entre éleveurs et agriculteurs, les terres cultivées s'appauvrissent, les disponibilités en biomasse fourragère limitent l'élevage et, de ce fait, la productivité de la terre et du travail diminue (8). Face à cela, les paysans diversifient et délocalisent leurs activités pour maintenir des revenus à un niveau acceptable. Les transferts monétaires liés aux activités non agricoles et la migration permettent, comme c'est le cas dans le bassin arachidier au Sénégal, de maintenir la traction animale dans les exploitations.

Les zones à forte densité de population rurale (plus de 60 hab./ $\mathrm{km}^{2}$ ) vont s'étendre dans les vingt prochaines années. Inversement, cet accroissement démographique qui touche aussi les villes s'accompagne d'une augmentation de la demande en produits alimentaires. Il existera davantage d'opportunités de marché pour les agriculteurs et les éleveurs s'ils arrivent à concurrencer les produits importés (du point de vue du prix mais aussi de la qualité). Il apparait donc prioritaire que la recherche et les structures d'appui travaillent pour accompagner ces mutations. Il s'agira de résoudre concomitamment, d'une part, des problèmes techniques permettant d'assurer une production de biomasse suffisante reposant sur le maintien, voire l'amélioration de la fertilité du sol (4) et, d'autre part, des problèmes économiques et organisationnels permettant aux producteurs ruraux de mieux se coordonner et de s'adapter aux exigences du marché.

Pour le moment, les producteurs dans les zones les plus peuplées ont plutôt opté pour une diversification de leurs activités de production. Mais certains se spécialisent en développant soit le maraîchage durant toute l'année, soit des systèmes d'élevage 
intensifs périurbains qui nécessitent de sécuriser l'approvisionnement en fourrage et en aliments du bétail. Des complémentarités entre systèmes de production ou petites régions (zone rurale à vocation fourragère et zone d'élevage périurbain, par exemple) pourraient ainsi se développer, tandis que des filières émergentes pourraient s'enrichir mutuellement : i) une filière fourrage, basée sur la production du fourrage par les exploitations sans élevage ayant atteint l'autosuffisance alimentaire qui vendraient ces fourrages aux agroéleveurs ou aux transhumants; ii) une filière traction animale dont les produits pourraient se diversifier (transport, production de viande et de lait) et ainsi s'en trouverait améliorée.

Le développement des synergies entre agriculture et élevage a été trop longtemps raisonné au niveau de l'unité de production de l'agriculteur, en privilégiant des approches techniques et en sousestimant les concurrences ou complémentarités entre paysans et pasteurs. La réduction des espaces de parcours communs bouleverse les systèmes de production des éleveurs (élevage extensif). Comment accompagner les éleveurs qui souhaitent se sédentariser et qui devront nécessairement intensifier leur système d'élevage (embouche, lait) en investissant certainement plus dans les productions végétales (cultures fourragères) ou en achetant une partie de leurs besoins fourragers? Les systèmes de production mixte agriculture élevage resteront diversifiés, mais l'on voit déjà poindre des convergences entre ce que les agriculteurs ont initié depuis une vingtaine d'années et ceux que les éleveurs sédentarisés sont en train de construire (mêmes utilisations de la traction animale, intérêt commun pour le maïs et l'embouche bovine, besoin commun en aliments du bétail...). Pour atteindre cet objectif de développement des synergies agriculture élevage qui contenterait tous les groupes de producteurs, il s'agit alors :

- d'amener ces producteurs à modifier leurs pratique, l'organisation de leur exploitation et la gestion de leurs moyens de production ;

- de définir des politiques agricoles favorisant les initiatives des agriculteurs et des éleveurs familiaux pour investir et mieux gérer les ressources naturelles qu'ils exploitent - sécurité foncière, développement du crédit, subvention ou réduction de la fiscalité pour certains équipements ;

- de concevoir avec les ruraux des instances de concertation efficaces pour régler les conflits pour l'accès aux ressources naturelles, pour définir une politique régionale d'aménagement du territoire (préservation des espaces à vocation pastorale) ou, plus simplement, pour développer des relations contractuelles entre différents types de producteurs.

\section{BIBLIOGRAPHIE}

1. BENOIT-CATTIN M., 1986. Les unités expérimentales du Sénégal. Montpellier, France, Cirad-DSA, $500 \mathrm{p}$.

2. BERGER M., 1996. L'amélioration de la fumure organique en Afrique soudano-sahélienne. Huit fiches techniques. Agric. Dév., nº hors série.

3. DJIMTOLOUM E., 2000. Etude des pratiques et des stratégies paysannes en matière de traction animale dans le sud du bassin arachidier du Sénégal (cas du village de Keur Bakary - communauté rurale de Kaymor). Montpellier, France, Cnearc, $92 \mathrm{p}$.

4. DONGMO NGOUTSOP A.L., 2003. De la culture attelée aux systèmes de culture sur couverture végétale : quelle recherche pour accompagner les évolutions des pratiques et des stratégies des agriculteurs au NordCameroun? In : Atelier Traction animale et stratégie d'acteurs : quelle recherche, quels services face au désengagement des Etats? BoboDioulasso, Burkina Faso, 17-21 novembre 2003.

5. DONGMO NGOUTSOP A.L., 2004. Simulation de l'effet du passage aux "systèmes de culture sur couverture végétale » sur les transferts de biomasse à l'échelle d'un terroir agropastoral. Le cas d'Ourolabo III. Garoua, Cameroun, Irad, 28 p.

6. DUGUE P., 1999. Utilisation de la biomasse végétale et de la fumure animale: impacts sur l'évolution de la fertilité des terres en zones de savanes. Montpellier, France, Cirad-tera, 175 p.
7. DUGUE P., 2002. Recyclage des résidus de récolte en vue d'accroitre I'utilisation de la fumure organique: le cas du Sine Saloum (Sénégal). In : Dégradation des sols au Sahel: techniques et méthodes de lutte. Montpellier, France, Cnearc, p. 103-122. (Coll. Etudes et travaux)

8. DUGUE P., KONE F., KONE G., AKINDES F., 2004. Production agricole et élevage dans le centre du bassin cotonnier de Côte d'Ivoire. Développement économique, gestion des ressources naturelles et conflits entre acteurs. Cah. Agric., $13:$ 504-509.

9. DuGue P., VAlL E., LeCOMte P., KLEIN D., ROLLIN D., 2004. Evolution des relations entre l'agriculture et l'élevage dans les savanes d'Afrique de l'Ouest et du Centre. Un nouveau cadre d'analyse pour améliorer les modes d'intervention et favoriser les processus d'innovation. Ol., Corps gras, Lipides, $11:$ 268-276.

10. FAYE A., LANDAIS E., 1986. L'embouche bovine paysanne dans le Centre-Nord du bassin arachidier au Sénégal. Cah. Rech. Dév., n 9-10 : 113-120.

11. FREUD C., HANAK FREUD E., RICHARD J., THENEVIN P., 1997. La crise de l'arachide au Sénégal. Ol., Corps gras, Lipides, 4 : 26-28, 162-164.

12. KLEIN H.-D., 2003. Gestion et développement des plantes fourragères à usages multiples dans les savanes d'Afrique centrale et de I'Ouest. In : Jamin J.-Y., Seiny Boukar L., Floret C. Eds, Actes colloque Savanes africaines: des espaces en mutation, des acteurs face à de nouveaux défis, Garoua, Cameroun, mai 2002 (cédérom). Montpellier, France, Cirad.

13. LABONNE M., 2003. Le secteur de l'élevage au Cameroun et dans les provinces du grand Nord: situation actuelle, contraintes, enjeux et défis. In : Jamin J.-Y., Seiny Boukar L., Floret C. Eds, Actes colloque Savanes africaines: des espaces en mutation, des acteurs face à de nouveaux défis, Garoua, Cameroun, mai 2002 (cédérom). Montpellier, France, Cirad.

14. LANDAIS E., LHOSTE P., 1990. L'association agriculture-élevage en Afrique intertropicale: un mythe techniciste confronté aux réalités de terrain. Cah. Sci. Hum., $26:$ 217-235.

15. LERICOLLAIS A., 1999. Paysans Sereer, dynamiques agraires et mobilités au Sénégal. Paris, France, IRD, 668 p. (Coll. A travers champs)

16. LHOSTE P., 1987. L'association agriculture-élevage. Evolution du système agro-pastoral au Sine-Saloum (Sénégal). Maisons-Alfort, France, Cirad-lemvt. (Etudes et synthèses)

17. MAGANGA-MOUITY M., 2000. Traction animale, composante essentielle des stratégies paysannes: les pratiques actuelles face au désengagement de l'Etat. Cas du village de Yéri Gueye, bassin arachidier Centre-Nord, Sénégal. Bambey, Sénégal, Encr, 68 p.

18. MAZOYER M., ROUDART L., 1998. Histoire des agricultures du monde du néolithique à la crise contemporaine. Paris, France, Le Seuil, 505 p.

19. ORSTOM, 1984. Le Nord-Cameroun. Des hommes, une région. Paris, France, Orstom, 551 p. (Coll. Mémoires)

20. PELISSIER P., 1966. Les paysans du Sénégal. Civilisations agraires du Cayor à la Casamance. Saint-Yrieix, France, Imprimerie Fabrègue, 940 p.

21. REISS D., PICARD J., DJOUMESSI M., MOUSSA C., KENIKOU C., ONANA J., 1997. Trois situations d'usage des ressources pastorales en zone soudano-sahélienne. In : Seiny Boukar L., Poulain J.-F., Faure G. Eds, Agriculture des savanes du Nord-Cameroun : vers un développement solidaire des savanes d'Afrique centrale. Montpellier, France, Cirad-CA, p. 221-225

22. SOUGNABE P., 2003. Conflits entre agriculteurs et éleveurs dans la zone soudanienne du Tchad. Une étude comparée entre deux régions : le Moyen Chari et le Mayo-Kébi. In : Actes colloque Organisation spatiale et gestion des ressources et des territoires ruraux, Montpellier, France, 25-27 février 2003. Montpellier, France, Cirad, p. 305-312.

23. SOW F., BADIANE A., MALONEY M., 2004. L'embouche paysanne, un exemple d'adaptation de l'élevage traditionnel à la nouvelle situation agricole dans le bassin arachidier. Cah. Agric., 13 : 211-220.

24. VALL E., DONGMO NGOUTSOP A.L., ABAKAR O., MEYER C., 2002. La traction animale dans le nouveau contexte des savanes cotonnières du Tchad, du Cameroun, et de la République centrafricaine. I. Diffusion de la traction animale et sa place dans les exploitations. Revue Elev. Méd. vét. Pays trop., $55:$ : 117-128.

25. VALL E., LHOSTE P., ABAKAR O., DONGMO NGOUTSOP A.L., 2003. La traction animale dans le contexte en mutation de l'Afrique subsaharienne : enjeux de développement et de recherche. Cah. Agric., 12 : 219-226. 
Summary

Dugué P., Dongmo Ngoutsop A.L. Draft Animal Power and Mixed Farming in the Savannahs of West and Central Africa. From a Technicist Model to a Reasoned Integration of Activities at Different Scales of Management

In Subsaharan Africa, agronomists believed for a long time that the improvement of smallholding performance rested on agriculture and livestock integration. This farming model was based on draft animal power, forage production, breeding of dairy and meat cows, and restoration of manure. But this model has not been adopted by farmers as expected. In the Senegalese basin of groundnut production, in order to adapt to climatic hazards, farmers prefer the use of draft horses, which enables them to perform more rapidly the work on soil and crops. In North-Cameroon, the extension of cultivated areas through draft cattle power has been preferred to yield increases and manure production. This strategy is still possible in areas with low to middle density populations, whereas in highly populated areas, the evolution of farming systems is similar to those observed in the Senegalese basin of groundnut production: development of draft donkey power and cattle fattening, difficulties in combining extensive animal husbandry with agricultural activities. However, at the scale of large regions, it will still be necessary to exploit lands unsuitable for cultivation through stock breeding. The access of transhumant animals to these pasture areas has to be preserved. Complementarities between periurban animal husbandry and neighboring agricultural zones could be used to develop commodity channels for forage supply and animal feed. At the village and small farm levels, the intensification of stock breeding is essential, but it will first be necessary to improve herd management, and above all forage production and rules of pasture management. Thus, draft animal power has to be mobilized to provide transport (manure, forage), increase incomes (dairy draft cows, fattening of end-of-career draft cows) and contribute to developing more productive farming systems including forage production.

Keywords: Mixed farming - Farming system - Draft Animal cultivation - Animal power - Land management - Rural development - Regional development - Africa south of Sahara.

\section{Resumen}

Dugué P., Dongmo Ngoutsop A.L. Tracción animal y asociación agricultura-cría en las sabanas de Africa del oeste y central. De un modelo técnico a una gestión de integración razonada a diferentes niveles

En Africa sub sahariana, los agrónomos han considerado durante mucho tiempo que el mejoramiento de los rendimientos de las explotaciones agrícolas reposaba sobre la integración de la cría a la agricultura. Este modelo de producción se apoyaba sobre la tracción animal, los cultivos forrajeros y la cría de bovinos de carne y de leche, base de la producción de abonos orgánicos. Pero este modelo no fue adoptado como previsto. En la cuenca de cacahuetes de Senegal, en un contexto de grandes cambios climáticos, la prioridad de los campesinos es de trabajar rápidamente para plantar y mantener los cultivos, lo que explica la preferencia por la tracción equina. En el norte de Camerún, la estrategia de agrandamiento de las superficies cultivadas, apoyándose en la tracción bovina, fue preferida a la del aumento de los rendimientos. El abono animal ha sido relegado durante mucho tiempo. Esta estrategia es aún posible en las zonas poco o medianamente pobladas. En las zonas más pobladas, las evoluciones de los sistemas de producción son comparables a las observadas en la cuenca de cacahuetes: desarrollo de la tracción con asnos y del engorde bovino, dificultad de asociar cría bovina extensiva y agricultura. En la escala de regiones más vastas, será siempre necesario valorizar, mediante la cría, los espacios difíciles para cultivo. El acceso a estos espacios para hatos nómadas debe ser preservado. Puede también considerarse el desarrollo de complementos entre los sistemas de cría peri urbana y de las zonas agrícolas cercanas, que desarrollarían filiales de abastecimiento en forrajes y en alimentos para el ganado. Al nivel de los terrenos pueblerinos y de las explotaciones agrícolas, la intensificación de la cría es indispensable pero necesita revisar los trayectos de los hatos y, sobre todo, aumentar la producción y las reglas de manejo de la biomasa vegetal. Para esto, la tracción animal debería movilizarse más para asegurar los transportes (abono, forraje, etc.), aumentar los ingresos (vacas de ordeño, engorde de los animales de ordeño en fin de carrera) y contribuir al desarrollo de sistemas de cultivo más productivos, acordando un lugar mayor a la producción de forrajes.

Palabras clave: Explotación agrícola combinada - Sistema de explotación - Cultivo a tracción animal - Energía animal Ordenación de tierras - Desarollo rural Desarollo regional Africa al sur del Sahara. 